Experts and Academy of Family Physicians of India position statement on preventing violence against health-care workers and vandalization of health-care facilities in India. Int J Crit IIIn Inj Sci. 2017 Apr-Jun; 7(2):7983.
8. Sriram V, Hyder AA, Bennett S. The Making of a New Medical Specialty: A Policy Analysis of the Development of Emergency Medicine in India. Int J Health Policy Manag. 2018 Nov; 7(11):993-1006.

\title{
On the absence of a doctor's dilemma in India: Reflections on impatient violence
}

\section{R Srivatsan}

On June 10, 2019, Mohammed Sayeed, a 75-year-old patient was admitted to the Nil Ratan Sircar Medical College and Hospital, Kolkata, West Bengal (1). He died that night due to a cardiac arrest and this led to a scuffle between the patient's family and duty doctors. In retaliation, the doctors refused to discharge the body, asserting that since the family claimed it was a suspicious death, a post-mortem was required. A mob arrived, and in the confrontation, a doctor was injured. The medicos struck work. Doctors and medical associations across the country have voiced unanimous support for the doctors, and called for protective legislation against the violence of the public. As a consequence of these nationwide doctors' protests, the Supreme Court has now proposed a law that protects doctors by severely punishing those who attack them (2). Meanwhile, it does seem as if such attacks are increasing.

The Telegraph carried three accounts of the incident: that of the duty doctors, the relatives, and the police (3). The differences in perspective are striking, as are the "facts" of the case. The doctors' version is indignant, the patients' family say their heads were "overheated" (matha garam ho gaya), and the police say there was a pitched battle when the doctors attacked the mob and police (3). Which is the true story? As the English historian EH Carr once said, facts are fish that swim around in the ocean (4), especially in such a rapidly politicising situation. The fish you catch determine the story you tell.

The wise doctor's dilemma should be to decide on the correct story to tell and the appropriate step to take. But for some reason, there is only the thoughtless conviction that they have been wronged, are perpetually at risk, and that draconian protection is needed.

\section{Statistical insight}

In order to put the patient's death, the doctors' demands and the government's response in perspective, it would be

Author: Srivatsan R (r.srivats@gmail.com), Independent Researcher on the politics of healthcare, development administration and tribal welfare in India; former Senior Fellow, Anveshi Research Centre for Women's Studies, Hyderabad INDIA.

To cite: Srivatsan R. On the absence of a doctor's dilemma in India: Reflections on impatient violence. Indian J Med Ethics. 2019 Oct-Dec;4(4) NS:332-3. DOI: 10.20529/JJME.2019.066

OIndian Journal of Medical Ethics 2019 useful to look at some statistical data. The Indian census, civil registration and sampling exercises (5), despite imperfections, are useful; more especially so the Sample Registration System statistical report (6), which, using large sample sizes, estimates vital statistics across the country. There have been criticisms and queries about the accuracy of these data collection systems (7), but for our purposes they will suffice even if they are only fifty percent accurate. The last section of the SRS Report of 2016 shows the distribution of deaths between public and private hospitals, external medical supervision, unqualified supervision and other situations (6:p 180).

Let us look at the West Bengal statistics:

- Population: 91.28 million in the 2011 Census (likely to be higher today).

- Estimated Crude Death Rate (6: p 122): 5.8 per 1000 population or about 529,400 as per the 2011 population. Reporting of deaths within the country is reasonably accurate with the CRS indicating that 82 percent of deaths were registered in 2016. ${ }^{1}$ (8: Statement $2, \mathrm{p} 2$ ).

- Nearly $33 \%$ of these deaths occur in government hospitals (6: p 180)-approximately 176,467 . With even a $50 \%$ error in the sample-based estimates ("inefficient government systems", eg), this figure is an adequate indicator of the scale of the problem of violence. This of course includes hospital-based deaths of infant and mothers, the aged, those afflicted with terminal diseases, and due to acute events. Break-ups along these categories are not easily available but could be one additional pointer to a more nuanced causation.

Now remember that most of these 176,467 hospital-based deaths were mourned by family, friends and community. So, even if say $200+$ violent confrontations have occurred the past year before the current incident ${ }^{2}, 176,267$ deaths have occurred in hospitals without violence. What then is the reason for the striking junior doctors' explosive rage in these specific instances? The only way I understand it is that many patient deaths in hospitals are handled by a relatively small number of frontline duty doctors. Exceptional violence in this event is faced by an even smaller number. As all these duty doctors experience and manage the routine flow of patient deaths, violent encounters stand out as an assault on their identity as committed professionals. 
My point here is not to dismiss these encounters. Yet, nearly $99.8 \%$ of these deaths have been handled peacefully. Given failing infrastructure, lack of resources, time crunch, overload, stress and pressure from seniors, first line doctors do a commendable job. What has gone wrong? Have some doctors been callous? Are the families of some of the deceased unreasonable? Or are junior doctors simply calling attention to their plight?

Why haven't the majority of other doctors (both senior and junior), drawing on their own individual experiences of handling death with dignity, not attempted to comprehend the problem and to mediate the current confrontation? Why have they instead joined this agitation as one body - a "corporation" of doctors seeing this violence as an affront to their identity?

\section{Agony, mistrust, anger}

The Twitter feeds of the young NRS Hospital doctors display anger and dismay (9). One post goes, “We aren't Gods. We don't want to be worshipped. Just treat us as what we are: Humans. That should be enough".

Curiously, a decade ago, a political party leader who lent similar support to a dead patient's family in a Hyderabad government hospital said: "The poor are not stupid. They don't think the doctor is God, that he can bring people back from death, only Allah has that power. They do expect some attention, some care for themselves, for people they love.[...] But these people don't even treat them like human beings!" (10).

There is clearly a lack of love between brusque doctors and unruly patient families - with the ripple effect that all patients suffer as all doctors strike work in solidarity. There is no sign of retrospection/reflection among the body of doctors regarding a social protocol to deal with traumatised attenders (aside from the crucial absence of medical protocols like patient triage in emergency wards to minimise such deaths in acute events by fast track diagnosis and response! (11)).

\section{Portents}

The larger horizon is the asphyxiation of public health infrastructure, privatisation of care, and costly medical education focused on profitable specialty. There is no space for a vision of healthcare, no time to teach commitment to the poor, and public hospitals become increasingly desolate corridors through which one hurries seeking elusive professional success beyond. The lack of a meaningful relationship with the ill, dying and bereaved in these instances, and the corporate rage of doctors are symptoms of this malaise. It is clearly a sign of the times that an unreflective Supreme Court has proposed draconian measures to protect doctors. It is unsurprising that the Health Minister Harsh Vardhan too came up with a knee-jerk response, with a call to punish perpetrators of these violent incidents (12).

Perhaps in the looming dystopia, doctors in hospitals will dispense life across a protective iron grill as do wine shops liquor in many Indian towns.
Unless they begin to think about their social roles.

\section{Acknowledgements}

I am deeply thankful to Rohini Raman, Lakshmi Kutty and Mithun Som of the newly emerging Anveshi Health Group for their sharp and useful feedback. I also acknowledge the discussions on the MFC and the Jan Swasthya Abhiyaan egroups

\section{Notes}

In general, the Sample Registration Service data is seen as an accurate estimate, while the percentage of this estimate registered by the Civil Registration System, called the level of registration, is seen as a measure of the efficacy of the registration system on the ground.

2 There are unconfirmed reports in Tweets and personal communications that when the Calcutta medical student unions met the media after this death, they released a press statement that there were 245 such attacks so $\mathrm{far}-$ the period during which this happened is unclear.

\section{References}

1. TT Bureau. NRS Medical College junior doctors assaulted. The Telegraphindia.com. 2019June 12[cited 2019 Oct 14]. Available from: https://www.telegraphindia.com/states/west-bengal/nrs-medicalcollege-junior-doctors-assaulted/cid/1692258

2. Legal correspondent.Plea wants violence against doctors made separate penal offence. The Hindu.com. 2019 Sep 6[cited 2019 Oct 13]. Available from: https://www.thehindu.com/news/national/plea-wants-violenceagainst-doctors-made-separate-penal-offence/article29352806.ece

3. The Telegraph in Calcutta. What happened at NRS Medical College and Hospital? The accounts. The Telegraphindia.com. 2019 Jun 12 [cited 2019 Oct 14]. Available from: https://www.telegraphindia.com/states/ west-bengal/what-happened-at-nrs-medical-college-and-hospitalthe-accounts/cid/1692259

4. Carr EH.What is History? Harmondsworth: Penguin Books, 1961. Reprint 1987.p 23.

5. Census of India website: http://censusindia.gov.in/

6. Registrar General and Census Commissioner India, Union Ministry of Home Affairs. SRS Statistical Report 2016 [cited 2019 Oct 15]. New Delhi: MoH; 2016. Available from: http://www.censusindia.gov.in/vital_ statistics/SRS_Reports_2016.html

7. Mahapatra P. An overview of the Sample Registration System in India. 2010[cited 2019 Oct 15]. Available from: http://unstats.un.org/unsd/ vitalstatkb/Attachment476.aspx?AttachmentType=1

8. Registrar General, Union Ministry of Home Affairs. Vital Statistics of India Based on the Civil Registration System 2016. New Delhi:MoH;2016 [cited 2019 Oct 14]. Available from: http://www.censusindia.gov. in/2011-Documents/CRS_Report/CRS\%20FINAL\%20REPORT\%20 2016_21062018.pdf

9. Twitter. \#NRSMCH. Available from: https://twitter.com/hashtag/ NRSMCH?src=hash\&ref_src $=$ twsrc\% 5 Etfw

10. Zachariah A, Srivatsan $R$, Tharu S, editors. Towards a critical medical practice: Reflections on the dilemmas of medical culture today. Hyderabad: Orient Blackswan; 2010.p 169-170.

11. Nagral S. Doctors and patients deserve better.Thehindu.com. 2019 Jun 19 [cited 2019 Oct 14]. Available from: https://www.thehindu.com/ opinion/op-ed/doctors-and-patients-deserve-better/article28067093. ece

12. PTI. Harsh Vardhan asks states to consider enacting law to protect doctors. Businessstandard.com. 2019 Jun 15[cited 2019 Oct 14]. Available from: https://www.business-standard.com/article/ptistories/consider-enacting-law-to-protect-medical-professionals-fromviolence-health-minister-to-states-119061500414_1.html 